\title{
Does behavioral intervention affect intention to quit? : A quasi- experimental study from primary healthcare settings in India
}

\author{
Rajmohan Panda', Divya Persai', Sandeep Mahapatra², Itismita Mohanty ${ }^{3}$
}

\begin{abstract}
INTRODUction Tobacco is the leading cause of death and disease in India. This study examines the effect of training intervention in behavioral counseling on intention to quit tobacco in primary healthcare settings in India. The intervention included training to improve behavioral counseling practices of primary care physicians (PCPs) based on the 5As approach to increase patients' motivation to quit tobacco.

METHODS A quasi-experimental design was used for the study. The intervention consists of training of primary care physicians in the behavioral intervention in tobacco cessation. The intervention was conducted in twelve districts of two states in India (Rajasthan and Odisha) in 2016-2017. Four districts were randomly sampled for the study. A total of 1314 participants (intervention and control) were recruited for the study in the baseline and end-line surveys, respectively. Intention to quit in 30 days was the primary outcome measure. Difference-indifference (DiD) logistic regression models were used separately for smokers and smokeless tobacco users to estimate the odds of intention to quit. Analysis was done in STATA Version 14.

RESULTS The intervention and time variable had a significantly positive influence on the intention to quit tobacco among smokers. Smokers in the intervention districts had higher odds of intention to quit ( $\mathrm{OR}=9.82$; 95\% CI: 1.67-57.72) compared to smokers in the control districts. Smokeless tobacco (SLT) users had higher odds of intention to quit (OR=3.06; 95\% CI: 1.35-6.98) in the end-line survey compared to baseline survey.

CONCLUSIONS Our findings indicate that building capacity in behavioral intervention in primary care settings can help increase the intention to quit among smokers. The observed difference in intention to quit between smokers and SLT users suggests the need of tailored counseling interventions for SLT users. There is a need for further research to design and evaluate training and behavioral interventions for SLT and dual (smoking and SLT) users in primary care settings in low- and middle-income countries.
\end{abstract}

AFFILIATION

1 Public Health Foundation of India, Gurugram, India

2 Evalueserve, Bangalore, India 3 Health Research Institute, University of Canberra, Canberra, Australia

CORRESPONDENCE TO Divya Persai. Public Health Foundation of India, Delhi National Capital Region, Gurugram, India.

E-mail: dpersai@gmail.com

\section{KEYWORDS}

tobacco cessation, behavioral intervention, low and middleincome countries

Received: 24 December 2020 Revised: 30 May 2021

Accepted: 14 June 2021

\section{INTRODUCTION}

Tobacco is the leading cause of death and diseases in India and innovative approaches to treat tobacco dependence and promote cessation are important to reduce morbidity and mortality amongst tobacco users. Globally, tobacco use claims more than 7 million lives every year ${ }^{1}$. India has the second largest consumption of tobacco with high prevalence of smokeless tobacco (21\%), smoking (11\%) and dual users $(29 \%)^{2}$. The WHO Framework Convention on Tobacco Control (FCTC) and MPOWER strategy (Monitor tobacco use and prevention policies; Protect 
people from tobacco smoke; Offer help to quit tobacco use; Warn about the dangers of tobacco; Enforce bans on tobacco advertising, promotion and sponsorship; Raise taxes on tobacco) recommends that tobacco control efforts should focus on tobacco use prevention and help promote cessation ${ }^{3}$. There is thus an urgent need to have a comprehensive strategy for cessation addressing all forms of tobacco.

Primary healthcare is the first port of call designed to provide preventive and promotive health care in low- and middle-income countries (LMICs) ${ }^{4}$. Primary healthcare clinics are natural settings for interventions to improve health behaviors for users as they can facilitate repeated contacts over a number of years (National Institute for Health, 2006) ${ }^{5}$. WHO advocated that tobacco cessation efforts be an integral part of primary healthcare. This includes routine advice on quitting tobacco use in all clinical encounters ${ }^{6}$. Clinicians in primary healthcare are well placed to use every patient contact as an opportunity for screening and advising patients against tobacco use. However, one significant barrier is how to effectively integrate behavioral counseling into these primary healthcare practices. Physicians can help patients quit, however they do not consistently or effectively provide cessation services. This is true in primary care practices in most LMICs including India. There have been some efforts to improve tobacco training among healthcare professionals in LMICs such as Project Quit Tobacco in India, Indonesia and the Smokescreen Education Program in China ${ }^{8,9}$. Health professionals who received specific training in cessation have a higher probability of performing tobacco cessation interventions. However, there is no strong evidence that this results in more people quitting tobacco use, e.g. out of eight studies, six did not find a significant effect on the cessation rates of patients ${ }^{10}$.

The primary goal of tobacco cessation interventions is to increase the intention to quit, quit attempts and quit rates. The challenges in quitting include low motivation to quit, poor self-efficacy and heavy nicotine dependence ${ }^{11}$. The $5 \mathrm{As}$ (ask, advice, assess, assist, and arrange) behavioral counseling approach rooted in behavior change theory can help individuals to quit ${ }^{12}$. However, the potential feasibility and effectiveness of such behavioral interventions in primary healthcare practices in
LMICs have not been fully evaluated.

Considering these factors, we designed a training intervention in behavioral interventions for primary care physicians (PCPs) and evaluated the intervention through a quasi-experimental design. Most training programs have simple metrics which focus on self-assessment and or clinical vignettes to test skills and competencies shortly after the training intervention ${ }^{13}$. We went a step further. Our study examined intention to quit amongst patients in the primary care practices after a year of the training intervention. We examined the intention to quit amongst smokers and smokeless tobacco (SLT) users separately. This is particularly relevant in the context of LMICs such as India where SLT use is an important part of the tobacco burden. In the present study, intervention and measures of outcome that are unique to smokers and SLT users in primary care have been examined. This knowledge is critical in in developing customized interventions in tobacco cessation in LMICs in primary healthcare.

\section{METHODS}

\section{Study design}

A quasi-experimental design was used for the study. The design of the study has been published elsewhere ${ }^{14}$. Similar to randomized trials, quasiexperiments can be used to demonstrate causality between an intervention and an outcome ${ }^{15}$.

\section{Study settings}

The data used in the study were collected through a cross-sectional survey conducted amongst patients using tobacco in primary care practice setting. These data are a subset of a project called Strengthening Cessation Capacity of Primary Care Professionals (SCCoPE). The SCCoPE project trained PCPs in behavioral interventions in two states in India: Rajasthan and Odisha in 2015. These states have high tobacco prevalence compared to national average (Odisha: 56\%; Rajasthan: 51\%; National average: 48\%; large rural population (Odisha 83\%; Rajasthan: $75 \%$ ) with extreme rural poverty (poverty head count (rural): Odisha 61\%, Rajasthan 36\% $)^{16,17}$.

\section{Sampling}

The intervention (training in behavioral intervention in tobacco cessation) was done in twelve districts of 
Rajasthan and Odisha, two districts were randomly sampled (one from each state) for the evaluation study. The selection of primary care practices was based on the non-communicable diseases (NCD) case load in the outpatient department. This was to increase the possibility of finding more patients with tobacco use. From the two intervention and control districts, 25 facilities were randomly selected. Control districts were comparable with the intervention districts in sociodemographic profile, prevalence of tobacco use and in the delivery of primary care services. The baseline and end-line surveys were done in the selected health facilities in November 2015 and October 2016, respectively.

\section{Intervention}

\section{Training Intervention}

The primary care physicians in the intervention facilities were trained in behavioral intervention in tobacco cessation. The training strategy was developed and implemented by a multidisciplinary group including experts on tobacco cessation. The training strategy included: 1) the identification of target groups; 2) the identification of the competencies that these target groups should have to be successful, through a baseline knowledge, skills and attitudes; and 3 ) the analysis of specific needs of the participants, learning styles, time availability, and disposition. The selection of physicians who received the training was made by state health authorities according to the following criteria: posting in the primary health center in the intervention districts and having internet access. The training was done through a cascadetraining model, which is a mechanism of delivering training from trainers from one cohort (state level) to trainees at the other cohort (district level) using tobacco cessation manuals ${ }^{18}$. The training manual was developed in consultation with leading cessation experts in India and the UK. The manual entailed necessary aspects of tobacco cessation, i.e. theories of tobacco addiction, behavioral and psychological approaches, and pharmacological approaches for tobacco cessation, patient follow-up, and evaluation of cessation practices. The manual also entails details of the 5As approach in tobacco cessation. Trainers were selected from within the state training division, health department, and medical colleges. Two authors ${ }^{19,20}$ who were part of the state-level training monitored the quality and adherence of the district-level training.
The one day 8-h training was split into four sessions, which suited best to physician's timetable and their continuing education schedule. During the first session, the conceptual basis of addiction and its behavioral treatment were taught by means of an interactive workshop, with theoretical content linked to practical cases and open for questions. The two central sessions dealt with patient's willingness to quit and involved discussion about clinical cases and role-playing among the participants. During the last session, pharmacological therapies for cessation were discussed through interactive clinical cases. Resource materials such as a tobacco cessation manual, counseling guide, and patient education materials were given to participants for use in their clinical practice. This face-to-face training was supplemented by an online training module of 30 hours, which reinforced the cessation messages and had modules on improving communication skills for counseling patients. This online training module was automated and was accompanied by case studies and assessments of learning for each module.

\section{Physician-delivered intervention in tobacco cessation}

The intervention was offered by the primary care physician when the patient visited the primary care facility for a physician consultation for any illness or issues. The intervention was training in behavioral counseling based on the 5As approach: 1) ask about tobacco use, 2) advise quitting, 3) assess the subject's willingness to quit, 4) assist in the attempt to quit, and 5) arrange follow-up. Trained PCPs counselled patients on the negative consequences of tobacco use, acute and long-term risks. Physicians also discussed potential barriers that patients would encounter as they attempt quitting. Patients received self-help materials from PCPs to help them quit. The self-help materials summarized the relationships between tobacco use and tobacco-related diseases and the common misconceptions about quitting. Each session lasted about 10-15 minutes. Finally, all the patients received telephone follow-up at 1, 3 and 6 months after enrollment. Monitoring was done at random intervals to ensure adherence to the intervention.

The control group included patients who received usual care in primary care clinics in the control districts. In addition, patients in control facilities also received self-help materials on quitting tobacco. 


\section{Study participants}

The study participants were sampled from tobacco users who visited the selected health facilities during the study period. The participants included patients who are current tobacco users aged $>18$ years, residents of the area near the primary care practices and who accessed the health facility for preventive or curative services.

\section{Sample size}

A total of 1314 participants were sampled for the study. This sample includes both baseline (536) and end-line (778) participants from both intervention and control. The ratio of sample of intervention to control was $2: 1$. The sample size for intervention group and control group was 351 and 191, respectively, each for baseline and end-line. The sample size was estimated to provide $80 \%$ power to detect and $10 \%$ difference in end-line with a design effect of 2.5. Design effect of 2.5 implies that sample variance is 2.5 times bigger than it would be if the survey were based on the same sample size but selected randomly.

\section{Data collection}

We registered responses from eligible patients using an interviewer administered questionnaire. Interviewers were independent consultants hired for both baseline and end-line surveys. Information was collected on sociodemographic, tobacco use patterns, individual parameters of the Fagerström Test for Nicotine Dependence (FTND) scale, intention to quit tobacco in 30 days, and exposure to tobacco-related warnings. Sociodemographic factors included age, sex, education level (categorized as 'less than primary' and 'primary and above') and poverty status recorded as 'above' or 'below the poverty line'. Religion was recorded as either 'Hindu, Muslim, or Christian'. Caste of an individual is the basis of social hierarchical organization in India. The government of India has identified the castes occupying the lowest rung of social hierarchy as the most socially disadvantaged and indigenous people, and classified them as scheduled castes and scheduled tribes, respectively ${ }^{19}$. Number of visits to the healthcare facility that the patient made over the past 12 months was also recorded, categorized as ' $<3$ times' or ' $\geq 3$ times'.

An index of respondent's exposure to Information, Education and Communication (IEC) material on dangers of tobacco use was calculated. The index comprises three variables: if in the last 30 days, the respondent noticed any information about the dangers of smoking/using smokeless tobacco in any form at public places like buses, shops and cinema theatres. We summarized these variables using factor analysis and constructed an index of individual exposure to IEC material. The primary outcome was Intention to quit in 30 days, with response 'yes' or 'no'. The primary health center in India caters for 20000-30000 people, and a Community Health Center (CHC) covers a population of $80000-$ $120000^{20}$. The population covered by the health facility was divided by 1000 to reduce the size and fit in the regression model.

\section{Data analyses}

We have used difference-in-difference (DiD) logistic regression models separately for smokers and SLT users to estimate the odds of intention to quit. DiD is a quasi-experimental design used in cross-sectional surveys that makes use of data from treatment and control groups to estimate a causal effect. The approach removes biases in post-intervention period comparisons between the treatment and control group that could be the result from permanent or trends differences between those groups ${ }^{21}$. The corresponding equation for the $\mathrm{DiD}$ logistic regression is:

$\operatorname{logit}\left(y_{i j t}=1 \mid\right.$ Time, Intervention $)=C_{0}+C_{1}[$ Time $]+$ $C_{2}[$ Intervention $]+C_{3}[$ Time $\times$ Intervention $]+$ $C_{4}[$ Covariates]

Where $y_{i j t}$ is the outcome variable for individual $i$ in healthcare facility $j$ in time $t$. The main parameter of interest is $C_{3}$, the coefficient of an indicator variable with a value of 1 if the tobacco user visits a physician in one of the healthcare facilities in the intervention districts in the end-line survey and zero otherwise. This has been entered as an interaction variable between two indicator variables in the model: 1) if the person is from one of the intervention districts in these two states, and 2) if the survey is end-line, while the intervention and time variables are also included independently. We have calculated robust standard errors clustered at healthcare facilities level. Analyses were done in STATA Version 14.

Missing data

About $7.5 \%$ of SLT users $(67 / 885)$ and $18 \%$ of 
smokers (77/426) did not have information on age of initiation. We have imputed age at first use missing values separately for smokers and SLT users using multiple imputations.

\section{RESULTS}

The response rate of the survey was $80 \%$. Demographics and tobacco use status in the sample are presented in Tables 1 and 2 . The average age of tobacco users and age at initiation were about 50 and 20 years, respectively. About half of the tobacco users were from rural areas.

The results of the DiD logistic regression model are presented in Tables 1 and 2. Findings suggest that tobacco users who start consuming tobacco later in their life were less motivated to quit tobacco. In addition, motivation to quit decreases as the age advances. Education and employment have a positive and significant effect on intention to quit among SLT users.

About half of the tobacco users were willing to quit in 30 days. Tobacco users who had more than primary level of education were two and half times more likely to have an intention to quit compared to the tobacco users who were uneducated or educated less than primary level. Similarly, tobacco users who were salaried were more likely to have an intention to quit. Analysis of individual items of the FTND scale suggests that more than half of the smokers smoke the first bidi/cigarette within 5 minutes of waking up and smoke even if they are ill. The odds of intention to quit were about two times more for the SLT users who consume 1 pack per week $(\mathrm{OR}=1.73$; 95\% CI: 1.01-2.96) and about three times more for users that consume between 2 and 3 packs per week compared to users that consume more than 3 packs per week $(\mathrm{OR}=3.39 ; 95 \%$ CI: 1.90-6.04) (Table $1)$. Though not statistically significant, the results suggest that smokers who smoke 11-20 sticks per day were less motivated to quit compared to those who smoke up to 10 sticks of bidis/cigarettes per day $(\mathrm{OR}=0.39 ; 95 \%$ CI: 0.16-0.94) (Table 2$)$.

Analysis of previous quit attempts for the smokers reveals that the odds of intention to quit for those

Table 1. The difference-in-difference estimates model for smokeless tobacco users, Odisha and Rajasthan, India, 2015-2016 ( $\mathrm{N}=1314)$

\begin{tabular}{|c|c|c|c|c|}
\hline & \multirow[t]{2}{*}{ OR } & \multirow[t]{2}{*}{ S.E. } & \multicolumn{2}{|c|}{$95 \% \mathrm{CI}$} \\
\hline & & & Lower & Upper \\
\hline \multicolumn{5}{|l|}{ Demographic variables } \\
\hline $\begin{array}{l}\text { Age at first use of the tobacco product: } 818 \text { (67) non-missing (missing } \\
\text { and imputed) observations }\end{array}$ & $0.96^{*}$ & 0.02 & 0.92 & 1.00 \\
\hline Age & $0.98^{*}$ & 0.01 & 0.96 & 1.00 \\
\hline Male gender (1) & 0.89 & 0.26 & 0.50 & 1.59 \\
\hline Education: 1 if Primary school and above & $2.55^{* *}$ & 0.95 & 1.23 & 5.28 \\
\hline Marital status: 1 if the person is married & 0.74 & 0.18 & 0.46 & 1.18 \\
\hline \multicolumn{5}{|l|}{ Religion: Hindus and Sikhs } \\
\hline Muslims & 1.26 & 0.40 & 0.67 & 2.35 \\
\hline Christians & 3.72 & 2.79 & 0.85 & 16.21 \\
\hline Caste: 1 if the respondent belongs to $\mathrm{SC} / \mathrm{ST}$ & $1.64^{* *}$ & 0.33 & 1.11 & 2.44 \\
\hline Rural: 1 if the person lives in rural area & 1.37 & 0.25 & 0.96 & 1.97 \\
\hline \multicolumn{5}{|l|}{ Occupation: unemployed, housewife, student and retiree (base category) } \\
\hline Laborer & 1.13 & 0.36 & 0.61 & 2.10 \\
\hline Self-employed & 1.28 & 0.37 & 0.73 & 2.24 \\
\hline Salaried & $2.86^{* *}$ & 1.04 & 1.40 & 5.84 \\
\hline \multicolumn{5}{|l|}{ Intervention related variables } \\
\hline Intervention: 1 if the person belongs to one of the intervention districts & 1.33 & 0.53 & 0.61 & 2.90 \\
\hline End-line: 1 if end-line data & $3.06^{*}$ & 1.29 & 1.35 & 6.98 \\
\hline $\begin{array}{l}\text { Intervention end-line: } 1 \text { if the person belongs to one of the intervention } \\
\text { districts and from end-line data }\end{array}$ & 1.52 & 0.68 & 0.63 & 3.67 \\
\hline
\end{tabular}


Table 1. Continued

\begin{tabular}{|c|c|c|c|c|}
\hline & \multirow[t]{2}{*}{ OR } & \multirow[t]{2}{*}{ S.E. } & \multicolumn{2}{|c|}{$95 \%$ CI } \\
\hline & & & Lower & Upper \\
\hline \multicolumn{5}{|l|}{ Health facility level variables } \\
\hline Population covered by the facility/1000 & $0.99^{*}$ & 0.01 & 0.97 & 1.00 \\
\hline \multicolumn{5}{|l|}{ Individual variables } \\
\hline \multicolumn{5}{|l|}{ Smokeless tobacco types: gutkha \&t gutkha plus khaini (base category) } \\
\hline Khaini \&t nasal use of snuff & 0.88 & 0.28 & 0.47 & 1.66 \\
\hline Betel quid plus tobacco \& khaini + betel quid & 1.10 & 0.28 & 0.66 & 1.83 \\
\hline \multicolumn{5}{|l|}{ Tobacco consumption frequency } \\
\hline \multicolumn{5}{|l|}{ More than 3 packs per week (base category) } \\
\hline 1 pack per week & $1.73^{*}$ & 0.47 & 1.01 & 2.96 \\
\hline 2-3 packs per week & $3.39^{* *}$ & 1.00 & 1.90 & 6.04 \\
\hline \multicolumn{5}{|l|}{ Behavioral variables } \\
\hline \multicolumn{5}{|l|}{ Number of quit attempts in the last 12 months: $\leq 5$ (base category) } \\
\hline $6-10$ & 0.91 & 0.22 & 0.57 & 1.46 \\
\hline$>10$ & $0.26^{*}$ & 0.18 & 0.07 & 0.99 \\
\hline $\begin{array}{l}\text { Number of visits to a physician in last } 12 \text { months - } 1 \text { if the respondent } \\
\text { visited } 3 \text { or more times }\end{array}$ & $0.61^{*}$ & 0.12 & 0.42 & 0.89 \\
\hline A combined index of individual exposure to IEC material & 1.51 & 0.34 & 0.96 & 2.35 \\
\hline
\end{tabular}

SC/ST: scheduled castes/tribes. IEC: information, education and communication.

Table 2. The difference-in-difference estimates model for smokers, Odisha and Rajasthan, India, 2015-2016 ( $\mathbf{N}=1314)$

\begin{tabular}{|c|c|c|c|c|}
\hline & \multirow[t]{2}{*}{ OR } & \multirow[t]{2}{*}{ S.E. } & \multicolumn{2}{|c|}{$95 \% \mathrm{CI}$} \\
\hline & & & Lower & Upper \\
\hline \multicolumn{5}{|l|}{ Demographics } \\
\hline $\begin{array}{l}\text { Age at first use of the tobacco product: } 349 \text { (77) non-missing (missing } \\
\text { and imputed) observations }\end{array}$ & $0.93^{* *}$ & 0.02 & 0.90 & 0.97 \\
\hline Age & 0.97 & 0.02 & 0.94 & 1.01 \\
\hline Gender: 1 if male & 2.10 & 1.48 & 0.53 & 8.33 \\
\hline Education: 1 if Primary school and above & 1.83 & 0.77 & 0.80 & 4.19 \\
\hline Marital status: 1 if the person is married & 0.72 & 0.51 & 0.18 & 2.90 \\
\hline \multicolumn{5}{|l|}{ Religion: Hindus and Sikhs } \\
\hline Muslims & 1.15 & 0.47 & 0.52 & 2.56 \\
\hline Caste: 1 if the respondent belongs to SC/ST & 2.46 & 1.18 & 0.96 & 6.32 \\
\hline Rural: 1 if the person lives in rural area & 1.77 & 0.68 & 0.84 & 3.75 \\
\hline \multicolumn{5}{|l|}{$\begin{array}{l}\text { Occupation: unemployed, housewives, students and retirees (base } \\
\text { category) }\end{array}$} \\
\hline Laborer & 1.80 & 1.27 & 0.45 & 7.16 \\
\hline Self-employed & 1.87 & 1.33 & 0.47 & 7.53 \\
\hline Salaried & 3.15 & 2.51 & 0.66 & 14.98 \\
\hline \multicolumn{5}{|l|}{ Intervention related variables } \\
\hline Intervention: 1 if the person belongs to one of the intervention districts & 2.61 & 1.89 & 0.63 & 10.77 \\
\hline End-line: 1 if end-line data & 3.22 & 2.69 & 0.63 & 16.53 \\
\hline $\begin{array}{l}\text { Intervention end-line: } 1 \text { if the person belongs to one of the intervention } \\
\text { districts and from end-line data }\end{array}$ & $9.82^{* *}$ & 8.87 & 1.67 & 57.72 \\
\hline
\end{tabular}


Table 2. Continued

\begin{tabular}{|c|c|c|c|c|}
\hline & \multirow[t]{2}{*}{ OR } & \multirow[t]{2}{*}{ S.E. } & \multicolumn{2}{|c|}{$95 \% \mathrm{CI}$} \\
\hline & & & Lower & Upper \\
\hline \multicolumn{5}{|l|}{ Health facility level variables } \\
\hline Population covered by the facility/1000 & 1.01 & 0.02 & 0.98 & 1.05 \\
\hline \multicolumn{5}{|l|}{ Individual variables } \\
\hline \multicolumn{5}{|l|}{ Smoking tobacco types: bidi and bidi, cigar plus hookah (base category) } \\
\hline Cigarette, hookah and e-cigarette & 0.73 & 0.36 & 0.28 & 1.93 \\
\hline \multicolumn{5}{|l|}{ Tobacco consumption frequency: 0-10 sticks per day (base category) } \\
\hline 11-20 sticks per day & $0.39^{*}$ & 0.18 & 0.16 & 0.94 \\
\hline 21-30 sticks per day & 1.26 & 1.11 & 0.23 & 7.08 \\
\hline \multicolumn{5}{|l|}{ Behavioral variables } \\
\hline \multicolumn{5}{|l|}{ Number of quit attempts in the last 12 months: $\leq 5$ (base category) } \\
\hline $6-10$ & 1.70 & 0.68 & 0.77 & 3.73 \\
\hline$>10$ & 5.80 & 5.78 & 0.82 & 40.93 \\
\hline $\begin{array}{l}\text { Number of visits to a physician in last } 12 \text { months - } 1 \text { if the respondent } \\
\text { visited } 3 \text { or more times }\end{array}$ & 0.65 & 0.26 & 0.30 & 1.43 \\
\hline A combined index of individual exposure to IEC material & $5.05^{*}$ & 3.39 & 1.35 & 18.82 \\
\hline
\end{tabular}

SC/ST: scheduled castes/tribes. IEC: information, education and communication. ${ }^{* *} \mathrm{p}<0.01$ and ${ }^{*} \mathrm{p}<0.05$.

who have attempted quitting more than 10 times in the last 12 months are about six times higher $(\mathrm{OR}=5.80 ; 95 \%$ CI: $0.82-40.93)$ than those who attempted quitting up to five times (Table 2 ).

The population covered by the facility has a negative influence on the intention to quit among SLT users. The higher the population covered by the health facility the less likely were the patients having an intention to quit smokeless tobacco $(\mathrm{OR}=0.99$; 95\% CI: 0.97-1.0).

The intervention had a significantly positive influence on the intention to quit tobacco among smokers (Table 2). Smokers from intervention districts in the end-line survey had nine times higher odds of intention to quit compared to those in control districts $(\mathrm{OR}=9.82 ; 95 \% \mathrm{CI}: 1.67-57.72)$. SLT users who belonged to the intervention group also had a higher intention to quit compared to the control group but the results were not statistically significant $(\mathrm{OR}=1.33$; 95\% CI: 0.61-2.9). SLT users in the endline survey (compared to baseline), had higher odds of intention to quit ( $\mathrm{OR}=3.06$; 95\% CI: $1.35-6.98)$.

The combined index of the user's exposure to Information, Education and Communication (IEC) information on tobacco cessation reveals a significant association with intention to quit tobacco. Smokers and SLT users, who observed IEC information and health warnings, were five times $(\mathrm{OR}=5.05 ; 95 \% \mathrm{CI}$ : $1.35-18.82)$ and one and a half times $(\mathrm{OR}=1.51$; 95\% CI: 0.96-2.35) more likely to have an intention to quit, compared to those who did not observed IEC information. Further information on smokers and SLT users can be found in the Supplementary file.

\section{DISCUSSION}

The present study is amongst the few studies that have evaluated the effectiveness of a training intervention for improving cessation practices in primary care. The training focuses on educating primary care providers on evidence-based behavioral intervention. Our findings are consistent with the Global Adult Tobacco Survey, GATS-India 2016 data, which suggest that about $50 \%$ of tobacco users have an intention to quit $^{2}$. It is also comparable to the estimates from other LMICs such as Malaysia (58\%) and Thailand (40\%), and Bangladesh (36\%) in the South-East Asian region $^{22-24}$.

Intention to quit is one of the key steps in the process towards tobacco cessation ${ }^{25}$. It corresponds to the contemplation stage in the stages of change theory widely used to facilitate cessation ${ }^{26}$. Several studies have shown association of intention to quit 
tobacco with social and economic determinants ${ }^{22,23}$. Many of the sociodemographic predictors of quit intentions identified in this study are similar to those identified in previous studies ${ }^{23,24}$. Demographic factors such as age, education level, and employment, were predictors of intention to quit. Previous studies have been inconsistent about the association between age and intention to quit. A study conducted by Quian et al. ${ }^{27}$ found that quitting increased with age among Chinese smokers. On the other hand, study conducted by Islam et al. ${ }^{27}$ in India showed that quitting became difficult with increasing age ${ }^{27}$. Our study suggests that intention to quit decreases with increasing age. This might be due to higher level of nicotine dependence associated with prolonged use. While efforts aimed at helping tobacco users to quit should start at an early age, interventions tailored for long time tobacco users are important to achieve significant quit rates ${ }^{28}$.

Nicotine dependence is a significant barrier to quitting tobacco and individual constructs of the FTND scale are associated with intention to quit tobacco ${ }^{29}$. However, we did not find any correlation of individual constructs of the FTND scale and intention to quit. Consumption of fewer number of smokeless tobacco products was the only construct associated with intention to quit tobacco. This suggests the need to customize cessation interventions based on type and dependence level of tobacco products.

Consistent with previous literature, we found that a previous quitting attempt was a predictor of willingness to quit smoking ${ }^{30}$. We reason that tobacco users who have tried quitting before are more motivated to quit than tobacco users who are trying to quit recently. We believe motivation to quit is more difficult in tobacco users who have recently made a quit attempt as they struggle in coping with withdrawal symptoms. Thus, a training curriculum for PCPs in cessation should include case studies addressing coping mechanisms for recent quitters.

Primary healthcare encounters represent frequent and important opportunities for cessation. However, tobacco users do not receive cessation support during their visit to the healthcare facility ${ }^{31}$. Studies report that the barriers to provide cessation support include time constraints and increased patient load in busy health facilities in LMICs ${ }^{32,33}$. Our study suggests that when the primary care facility is catering to a large population then there is a negative influence on intention to quit among SLT users. One possible reason could be that PCPs cannot do customized interventions with SLT and dual users because of time restrictions. Our training focused on a simple adaptation of the 5As approach and helped improved counseling skills amongst PCPs. This worked for addressing smoking cessation. For patients using more than one type of tobacco (as may be the case for SLT users) complex behavioral interventions guided by strong integration of wellestablished and novel theoretical approaches maybe more useful and effective. The provision of such interventions would require more time and effort by PCPs. A team approach at the primary care practice with the involvement of the allied health professionals can help in providing this complex and contextualized cessation services for SLT and dual users.

The ' $W$ ' in the MPOWER strategy of WHO recommends implementation of the 'Warning about the dangers of tobacco' ${ }^{6}$. Many countries including India have graphic warnings on tobacco products. Our findings reveal that noticing antitobacco information and health warnings on tobacco products by tobacco users is associated with a higher intention to quit. The finding corroborates other studies and provides further evidence for the effectiveness of pictorial warnings on tobacco products.

Our findings clearly indicate that building capacity of PCPs in delivering behavioral intervention in real-life settings is effective for increasing intention to quit among smokers. The relative effect of the counseling intervention compared to the control was higher than reported previously ${ }^{34}$. Physicians may not implement cessation counseling because of perceived low efficacy of tobacco cessation counseling ${ }^{8}$. Ways to increase motivation for healthcare providers to counsel patients for cessation should be an integral part of the training curriculum. Based on our findings, we also recommend customizing the counseling for specific sub-groups of tobacco users based on types of tobacco use, frequency, and nicotine dependence. Trainings under the National Tobacco Control Programme 
(NTCP) need to address these sub-groups as they scale up cessation training programs for physicians and other allied healthcare providers.

Smokeless tobacco is consumed worldwide and its use results in avoidable morbidity and mortality. It leads to a loss of more than 6 million Disability Adjusted Life Years and a quarter of a million deaths ${ }^{35}$. When we compared baseline with endline, we found that SLT users had a higher intention to quit. While positive changes were observed in intention to quit rates amongst SLT users in intervention districts compared to control, the results were not statistically significant. This observed difference suggest that counseling sessions may trigger some change in SLT users, but in order to be more effective there is a need for training curricula to focus exclusively on SLT users. Smokeless tobacco consumption in India has strong sociocultural dimensions, which need to be considered while designing behavioral support interventions and training programs. As SLT cessation needs are different from smoking, adequate SLT cessation training would be the cornerstone of future success of SLT cessation initiatives.

Treating tobacco dependence is overshadowed by other policy priorities in tobacco control. Tobacco cessation is the only practical way to avoid many tobacco deaths worldwide before 2050. While both the FCTC and the WHO MPOWER package of effective country-level policies emphasize the strategy, only $15 \%$ of the world's population have access to appropriate cessation support ${ }^{36}$. A recent article notes that all the countries in the South-East Asian Region are lagging behind in the implementation of Article 14 of the WHO-FCTC ${ }^{37}$. There is a growing body of evidence supporting lowcost nation-wide cessation interventions including the delivery of brief cessation advice routinely during healthcare encounters ${ }^{8}$. A strong emphasis on building capacity for tobacco cessation and scalingup well designed low-cost cessation strategies can help to decrease mortality and morbidity related to tobacco use in LMICs.

Our study showed the effectiveness and feasibility of a training intervention for improving behavioral counseling based on 5As approach in the primary care settings in India. In the real world (primary healthcare settings), it is difficult to randomize subjects and quasi-experimental study designs such as ours can be considered for understanding effectiveness at the system level. This study provides the evidence for customizing tobacco cessation interventions in a busy primary care setting and has lessons for further expansion of tobacco cessation programs in LMIC. Our training modules have been used by both the intervention states in further expansion of the training beyond the 12 intervention districts. A session on addressing smokeless tobacco is now part of the cessation training curricula and has been adopted by the state NTCP divisions.

\section{Limitations}

In the present study, the sample was limited to patients visiting health facilities in two states and generalizability of the results is limited to similar sub-populations in the country. We relied on selfreported responses and this may be subject to recall bias. A balance between external and internal validity is important for quasi-experimental designs ${ }^{38}$. In this study, the external validity was maximized by having few exclusion criteria and by matching the control group which delivered usual care. Internal validity was maximized by decreasing contamination bias.

\section{CONCLUSIONS}

The findings of this study suggest that training PCPs in tobacco cessation could potentially improve utilization of cessation assistance and cessation rates in LMICs. Training modules on SLT cessation for different categories of health professionals and workers should be developed. As tobacco control interventions are scaled up in LMICs, rigorous evaluation of training programs for cessation should be a part of standard practice.

\section{REFERENCES}

1. World Health Organization. WHO report on the global tobacco epidemic, 2017: monitoring tobacco use and prevention policies. World Health Organization; 2017. Accessed January 1, 2020. https://apps.who.int/iris/ bitstream/handle/10665/255874/9789241512824-eng. pdf? sequence $=1 \&$ isAllowed $=y$

2. Tata Institute of Social Sciences, Mumbai and Ministry of Health and Family Welfare, Government of India. Global Adult Tobacco Survey GATS 2 India 2016-17. 2018. Accessed May 30, 2020. https://ntcp.nhp.gov.in/assets/ document/surveys-reports-publications/Global-Adult- 
Tobacco-Survey-Second-Round-India-2016-2017.pdf

3. World Health Organization. WHO Framework Convention on Tobacco Control. World Health Organization; 2003. Accessed February 2, 2020. http://apps.who.int/ iris/bitstream/handle/10665/42811/9241591013. pdf? sequence $=1$

4. De Maeseneer J, Moosa S, Pongsupap Y, Kaufman A. Primary health care in a changing world. Br J Gen Pract. 2008;58(556):806-ii. doi:10.3399/bjgp08X342697

5. National Institute for Health and Care Excellence. Brief interventions and referral for smoking cessation in primary care and other settings. National Institute for Health and Clinical Excellence; 2006. Public Health Intervention Guidance no.1. Accessed January 2, 2020. http://www.ncsct.co.uk/usr/pub/guidance-on-briefinterventions-and- referral-for-smoking.pdf

6. World Health Organization. MPOWER: A Policy Package to Reverse the Tobacco Epidemic. World Health Organization; 2008. Accessed January 2, 2020. http:// www.who.int/tobacco/mpower/mpower_english.pdf

7. West R, Raw M, McNeill A, et al. Health-care interventions to promote and assist tobacco cessation: a review of efficacy, effectiveness and affordability for use in national guideline development. Addiction. 2015;110(9):13881403. doi:10.1111/add.12998

8. Nichter M, Nichter M, Muramoto M. Project Quit Tobacco International: Laying the Groundwork for Tobacco Cessation in Low- and Middle-Income Countries. Asia Pac J Public Health. 2010;22(3 suppl):181S-188S. doi:10.1177/1010539510373023

9. Richmond R. The process of introducing a tobacco curriculum in medical school. Respirology. 2004;9(2):165172. doi:10.1111/j.1440-1843.2004.00578.x

10. Olano-Espinosa E, Matilla-Pardo B, Minué C, Antón E, Gómez-Gascón T, Ayesta FJ. Effectiveness of a health professional training program for treatment of tobacco addiction. Nicotine Tob Res. 2013;15(10):1682-1689. doi:10.1093/ntr/ntt040

11. Feng G, Jiang Y, Li Q, et al. Individual-level factors associated with intentions to quit smoking among adult smokers in six cities of China: findings from the ITC China Survey. Tob Control. 2010;19(Suppl 2):i6-i11. doi:10.1136/tc.2010.037093

12. Vallis M, Piccinini-Vallis H, Sharma AM, Freedhoff Y. Modified 5 As: Minimal intervention for obesity counseling in primary care. Can Fam Physician. 2013;59(1):27-31. Accessed May 30, 2021. https://www. cfp.ca/content/cfp/59/1/27.full.pdf

13. Hudelson P, Perron NJ, Perneger T. Using clinical vignettes to assess doctors' and medical students' ability to identify sociocultural factors affecting health and health care. Med Teach. 2011;33(10):e564-e571. doi:10.3109/0142159X.2011.602994

14. Panda R, Mahapatra S, Gaurav K, Pati S, Mathur MR. A quasi-experimental intervention to assess the effectiveness of a physician-delivered tobacco cessation intervention in India: A detailed study protocol. SAGE Open Med. 2017;5:1-8. doi:10.1177/2050312117697173

15. Grimshaw J, Campbell M, Eccles M, Steen N. Experimental and quasi-experimental designs for evaluating guideline implementation strategies. Fam Pract. 2000;17(suppl 1):S11-S16. doi:10.1093/fampra/17.suppl_1.s11

16. Ministry of Health and Family Welfare, Government of India. Global Adult Tobacco Survey: India 2009-2010. Accessed May 30, 2021. https://www.who.int/tobacco/ surveillance/survey/gats/gats_india_report.pdf?ua=1

17. Office of the Registrar General and Census Commissioner. Census India. Accessed June 1, 2020. http://censusindia. gov.in/

18. Karalis T. Cascade Approach to Training: Theoretical Issues and Practical Applications in Non - Formal Education. Journal of Education \& Social Policy. 2016;3(2):104-108. Accessed May 30, 2021. http:// jespnet.com/journals/Vol_3_No_2_June_2016/12.pdf

19. Ghauhan CPS. Education and caste in India. Asia Pacific J Educ. 2008;28(3):217-234. doi:10.1080/02188790802267332

20. Directorate General of Health Services, Ministry of Health and Family Welfare, Government of India. Indian Public Health Standards (IPHS) For Primary Health Centres: GUIDELINES. Directorate General of Health Services, Ministry of Health and Family Welfare, Government of India; 2006. Accessed May 30, 2021. http://www. iapsmgc.org/userfiles/4IPHS_for_PHC.pdf

21. Lechner M. The Estimation of Causal Effects by Difference-in-Difference Methods. Foundations and Trends ${ }^{\circledR}$ in Econometrics. 2011;4(3):165-224. doi:10.1561/0800000014

22. Li L, Borland R, Yong HH, et al. Predictors of smoking cessation among adult smokers in Malaysia and Thailand: Findings from the International Tobacco Control Southeast Asia Survey. Nicotine Tob Res. 2010;12(Suppl 1):S34-S44. doi:10.1093/ntr/ntq030

23. Driezen P, Abdullah AS, Quah ACK, Nargis N, Fong GT. Determinants of intentions to quit smoking among adult smokers in Bangladesh: findings from the International Tobacco Control (ITC) Bangladesh wave 2 survey. Glob Health Res Policy. 2016;1:11. doi:10.1186/s41256-016-0012-9

24. Qian J, Cai M, Gao J, Tang S, Xu L, Critchley JA. Trends in smoking and quitting in China from 1993 to 2003: National Health Service Survey data. Bull World Health Organ. 2010;88(10):769-776. doi:10.2471/BLT.09.064709

25. Panda R, Venkatesan S, Persai D, Trivedi M, Mathur MR. Factors determining intention to quit tobacco: exploring patient responses visiting public health facilities in India. Tob Induc Dis. 2014;12(January):1-10. doi:10.1186/1617-9625-12-1

26. Daoud N, Hayek S, Muhammad SA, et al. Stages of change of the readiness to quit smoking among a random sample of minority Arab -male smokers in Israel. BMC Public 
Health. 2015;15:672. doi:10.1186/s12889-015-1950-8

27. Islam K, Saha I, Saha R, Samim Khan SA, Thakur R, Shivam S. Predictors of quitting behaviour with special reference to nicotine dependence among adult tobacco-users in a slum of Burdwan district, West Bengal, India. Indian J Med Res. 2014;139(4):638-642. Accessed May 30, 2021. https://www.ijmr.org.in/temp/ IndianJMedRes1394638-3294936_090909.pdf

28. Tait RJ, Hulse GK, Waterreus A, et al. Effectiveness of a smoking cessation intervention in older adults. Addiction. 2007;102(1):148-155. doi:10.1111/j.1360-0443.2006.01647.x

29. Hyland A, Borland R, Li Q, et al. Individual-level predictors of cessation behaviours among participants in the International Tobacco Control (ITC) Four Country Survey. Tob Control. 2006;15(suppl 3):iii83-iii94. doi:10.1136/tc.2005.013516

30. Hyland A, Li Q, Bauer JE, Giovino GA, Steger C, Cummings KM. Predictors of cessation in a cohort of current and former smokers followed over 13 years. Nicotine Tob Res. 2004;6(suppl 3):S363-S369. doi:10.1080/14622200412331320761

31. Van Schayck OCP, Williams S, Barchilon V, et al. Treating tobacco dependence: guidance for primary care on life-saving interventions. Position statement of the IPCRG. NPJ Prim Care Respir Med. 2017;27(1):38. doi:10.1038/s41533-017-0039-5

32. Abdullah AS, Stillman FA, Yang L, Luo H, Zhang Z, Samet JM.Tobacco Use and Smoking Cessation Practices among Physicians in Developing Countries: A Literature Review (1987-2010). Int J Environ Res Public Health. 2014;11(1):429-455. doi:10.3390/ijerph110100429

33. Panda R, Persai D, Mathur M, Sarkar BK. Perception and Practices of Physicians in Addressing the Smokeless Tobacco Epidemic: Findings from Two States in India. Asian Pac J Cancer Prev. 2013;14(12):7237-7241. doi:10.7314/apjcp.2013.14.12.7237

34. Stead LF, Buitrago D, Preciado N, Sanchez G, HartmannBoyce J, Lancaster T. Physician advice for smoking cessation. Cochrane Database Syst Rev. 2013;(5):CD000165. doi:10.1002/14651858.CD000165.pub4

35. Siddiqi K, Shah S, Abbas SM, et al. Global burden of disease due to smokeless tobacco consumption in adults: analysis of data from 113 countries. BMC Med. 2015;13:194. doi:10.1186/s12916-015-0424-2

36. World Health Organization. WHO report on the global tobacco epidemic, 2015: Raising taxes on tobacco. 2015. Updated July 2015. Accessed January 2, 2020. https://apps.who.int/ iris/bitstream/handle/10665/178574/9789240694606_ eng.pdf? sequence $=1$

37. World Health Organization. 2014 global progress report on implementation of the WHO Framework Convention on Tobacco Control. 2014. Accessed January 2, 2020. http:// www.who.int/fctc/reporting/2014globalprogressreport. pdf
38. Handley MA, Lyles CR, McCulloch C, Cattamanchi A. Selecting and Improving Quasi-Experimental Designs in Effectiveness and Implementation Research. Annu Rev Public Health. 2018;39:5-25. doi:10.1146/annurevpublhealth-040617-014128

\section{ACKNOWLEDGMENTS}

We thank all the study participants. We also thank physicians and healthcare providers at primary care facilities in the two states for supporting the conduct of study.

\section{CONFLICTS OF INTEREST}

The authors have each completed and submitted an ICMJE form for disclosure of potential conflicts of interest. The authors declare that they have no competing interests, financial or otherwise, related to the current work. R. Panda reports that this study was an evaluation of a training grant funded by Pfizer Independent grant for learning change (IGLC).

\section{FUNDING}

The project SCOPE was supported by IGLC (Independent Grants for Learning \& Change; grant number 13197253) by Global Bridges. The funding supported in the designing, data collection and conduct of the study.

\section{ETHICAL APPROVAL AND INFORMED CONSENT}

Ethical approval for this study was obtained from Public Health Foundation of India Ethical committee (Approval number: IEC No: RC-IEC-258/15). A written informed consent to participate in the study was obtained from all participants.

\section{DATA AVAILABILITY}

All data supporting this research can are included in this published article.

\section{AUTHORS' CONTRIBUTIONS}

$\mathrm{RP}, \mathrm{DP}, \mathrm{IM}$ and SM conceptualized and planned the overview of the manuscript. RP was involved in designing and conducting the study as well as the design of the manuscript. DP contributed to the interpretation and writing of the results and discussion. IM led the data analysis and contributed to the methods and results sections of the manuscript. All authors read and approved the final manuscript.

\section{PROVENANCE AND PEER REVIEW}

Not commissioned; externally peer reviewed. 